Thorax (1970), 25, 223.

\title{
Heart disease and pneumoconiosis
}

\author{
W. L. SA N DER S ${ }^{1}$ \\ Pneumoconiosis Medical Panel, Birmingham
}

\begin{abstract}
This paper presents an investigation into the relative frequency of deaths from coronary artery disease and from congestive cardiac failure associated with or secondary to chronic lung disease in 367 men with pneumoconiosis. All these men had bzen receiving a pension for pneumoconiosis and had died in the area served by the Birmingham Pneumoconiosis Medical Panel during 1967 and 1968. Of the total, 76 died from coronary artery disease and 107 from congestive cardiac failure. Thirty-one men had simple pneumoconiosis alone, and of these $87 \%$ died from coronary artery disease and $13 \%$ from congestive cardiac failure. Sixty-one men had progressive massive fibrosis, and of these $10 \%$ died from coronary artery disease and $90 \%$ from congestive cardiac failure. Ninety-one men had simple pneumoconiosis with bronchitis and emphysema and in this group death occurred in approximately equal numbers from both causes. It is suggested that the reason for these differences is the variation in the degree of hypoxia present in the different conditions.
\end{abstract}

\section{MATERIAL}

The series consists of 367 men who received a pension for pneumoconiosis and who died in the area served by the Birmingham Pneumoconiosis Medical Panel during 1967 and 1968. Three cases were excluded from the series, a woman who died from thrombo-embolic pulmonary hypertension, a man who died from fibrosing alveolitis and a man who died from hard metal disease. All the men had been examined in life by the Pneumoconiosis Medical Panel and all the lungs were examined at necropsy by members of the Panel. The necropsy findings on the heart were taken from the pathologist's report.

In arriving at the cause of death, in each case the man's medical boarding papers, radiographs, hospital case sheets or, if the man died at home, a description of the mode of death from the general practitioner, the pathologist's necropsy report and the Panel's description of the lungs were taken into account.

The minimum criterion for the diagnosis of progressive massive fibrosis was taken to be the radiological category B (International Labour Office, 1959). The equivalent of this category at necropsy was taken to be a mass not less than $5 \mathrm{~cm}$. in diameter.

1Present address: Department of Geriatrics, Warwick Hospital, Warwick
Bronchitis and emphysema were included in the cause of death where either of these conditions had been diagnosed in life or where either were present in the necropsy specimens. No criteria could be laid down for the diagnosis of either of these conditions in life, but where either had been recorded on the man's boarding papers it was accepted as having been present. Nor was any distinction made between the two conditions in life, because in clinical practice the terms tend to be used indiscriminately and to distinguish between the two from the documents available would have been impossible. Chronic bronchitis was diagnosed at necropsy where the bronchial walls were thickened and the bronchi contained pus or mucopus. When emphysema was present in the necropsy specimens, for the purpose of this paper no attempt was made to differentiate between panacinar and centrilobular emphysema. Death was accepted as being from coronary artery disease where there was a recent infarct, with or without thrombosis. When death was sudden in the presence of severe coronary artery disease and no other cause of death was found, it was presumed that death was due to ventricular fibrillation or asystole.

\section{FINDINGS}

The total breakdown of cases is shown in Table I.

This paper is concerned only with pneumoconiosis in relation to death from coronary artery 
disease and congestive cardiac failure associated with or secondary to chronic lung disease, so that only the first two groups in this table will be considered further.

\section{T A B L E I}

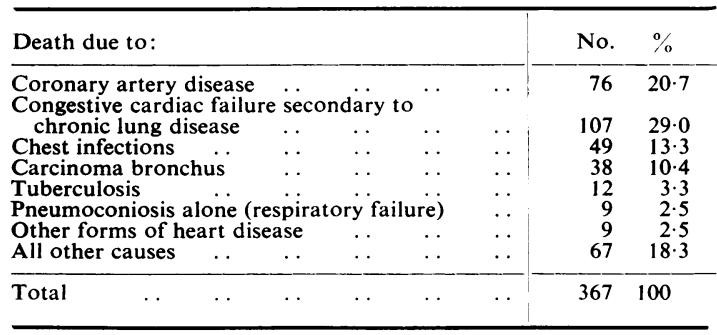

Because most previous series have consisted only of coal workers, an analysis of these two groups by trades is shown in Table II.

T A B L E I I

\begin{tabular}{|c|c|c|c|c|c|c|}
\hline \multirow[t]{2}{*}{ Trade } & & & \multicolumn{2}{|c|}{$\begin{array}{c}\text { Death from } \\
\text { Coronary Artery } \\
\text { Disease }\end{array}$} & \multicolumn{2}{|c|}{$\begin{array}{l}\text { Death from } \\
\text { Congestive } \\
\text { Cardiac Failure }\end{array}$} \\
\hline & & & No. & $\%$ & No. & $\%$ \\
\hline $\begin{array}{l}\text { Coal workers ... } \\
\text { Foundry workers } \\
\text { Refractories } \\
\text { Sandstone } \quad \ldots \\
\text { Pottery } \quad \ldots\end{array}$ & $\begin{array}{l}\cdots \\
\cdots \\
\cdots \\
\cdots\end{array}$ & $\begin{array}{l}\cdots \\
\cdots \\
\cdots \\
\cdots\end{array}$ & $\begin{array}{r}60 \\
14 \\
1 \\
1 \\
-\end{array}$ & $\begin{array}{r}79 \cdot 0 \\
18 \cdot 4 \\
1 \cdot 3 \\
1 \cdot 3 \\
-\end{array}$ & $\begin{array}{r}78 \\
26 \\
1 \\
1 \\
1\end{array}$ & $\begin{array}{r}73 \cdot 0 \\
24 \cdot 3 \\
0.9 \\
0.9 \\
0.9\end{array}$ \\
\hline Total & . & . & 76 & 100 & 107 & 100 \\
\hline
\end{tabular}

After consideration of all the evidence as to the cause of death, the relevant cases were allotted to one of the two groups, death from coronary artery disease or death from congestive cardiac failure. These two groups were then subdivided into four sub-groups (Table III) :

1. Simple pneumoconiosis (pn) alone

2. Simple pneumoconiosis with bronchitis and/ or emphysema

3. Progressive massive fibrosis (PMF) alone

4. Progressive massive fibrosis with bronchitis and / or emphysema

\section{DISCUSSION}

No account has been taken in this paper of the smoking histories of the men concerned because this information was incomplete. It is appreciated, however, that smoking may have had some bearing on the incidence of both coronary artery disease and bronchitis and emphysema, and hence on the development of congestive cardiac failure. Furthermore, since no differentiation has been
T A B L E I I I

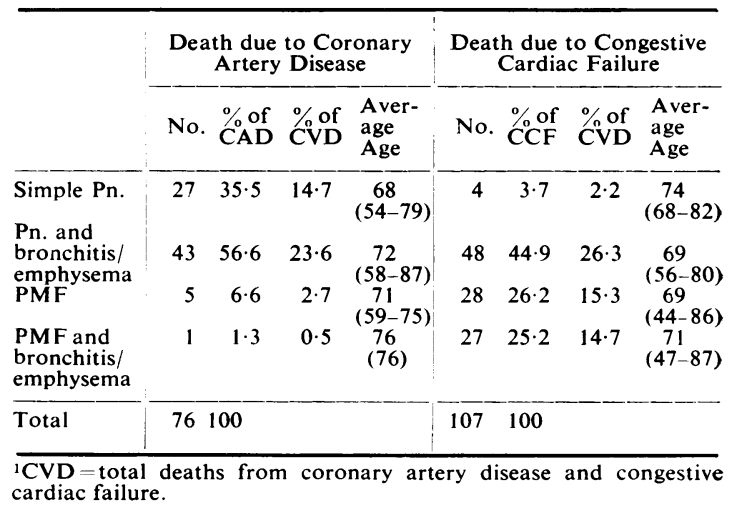

made between bronchitis and emphysema clinically, or between centrilobular and panacinar emphysema in the necropsy specimens, the relative importance of these in the causation of congestive cardiac failure cannot be assessed. Nevertheless, within these limits Table III shows that death from congestive cardiac failure is rare in men with simple pneumoconiosis alone, and that death occurs about equally from coronary artery disease and congestive cardiac failure in men with simple pneumoconiosis and bronchitis and emphysema. Death from coronary artery disease is rare in men with progressive massive fibrosis, with or without bronchitis and emphysema, but death from congestive cardiac failure is commonest in this group.

It has been shown before that there is a reduced incidence of myocardial infarction in patients with chronic airway obstruction (Mitchell, Walker, and Maisel, 1968), and it has been suggested that chronic hypoxia stimulates the development of inter-coronary anastomoses. Chronic hypoxia is also a powerful stimulus to coronary artery dilatation, and it is clear that a dilated artery is less liable to turbulence in the blood flow than a narrowed one, and hence less liable to the formation of mural thrombi.

Simple pneumoconiosis rarely causes right ventricular hypertrophy (Gough, 1965) and, though slight hypoxaemia may occur from category 2 upwards, at this stage there is no pulmonary hypertension and this has little or no disabling effect (Lavenne, 1968). Gooding (1946), in an analysis of 227 patients certified as having silicosis, found the cause of death to be congestive cardiac failure in $84(37 \%)$, in only four of whom were massive lesions absent, and these four had other cardiac abnormalities. Gooding did not distinguish between patients with or without bronchitis and 
emphysema. Lavenne (1951) found no instance of simple pneumoconiosis alone in 100 patients with congestive cardiac failure due to pneumoconiosis. Thus men with simple pneumoconiosis alone have no pulmonary hypertension to cause congestive cardiac failure and little or no hypoxaemia to cause coronary artery dilatation, and it is suggested that this accounts for the relatively high incidence of deaths from coronary artery disease in this group and the low incidence of deaths from congestive cardiac failure.

In patients with bronchitis and emphysema, pulmonary hypertension is frequent but by no means invariable. The causes of this pulmonary hypertension are complex, but it is generally agreed that the most important factor leading to its development is chronic hypoxia (Heath, 1968; Wyatt and Ishikawa, 1968). It therefore seems likely that in the group of patients with simple pneumoconiosis and bronchitis and emphysema the relative frequency of deaths from coronary artery disease and congestive cardiac failure depends in part on the degree of hypoxia present.

To produce obstructive pulmonary hypertension requires obliteration of two-thirds of the total cross-section of the pulmonary vascular bed and this rarely happens in emphysema (Wood, 1956). In progressive massive fibrosis the situation is different: in severe cases only a small portion of the vascular bed survives (Gough, 1965). Further, in severe cases the reduction of the pulmonary vascular bed of itself causes hypoxaemia (Lavenne, 1968). Thus in progressive massive fibrosis hypoxaemia is frequent and may cause coronary artery dilatation. This might be a factor in the low incidence of deaths from coronary artery disease in this group. On the other hand, the pulmonary hypertension of progressive massive fibrosis is irreversible, unlike that due to the chronic hypoxia of bronchitis and emphysema (Heath, 1968; Wyatt and Ishikawa, 1968; Editorial, 1969) and, in the final stages, progresses rapidly to congestive cardiac failure (Lavenne, 1968).

When bronchitis and emphysema are superimposed on progressive massive fibrosis the effects of both conditions are present. There is therefore a more severe degree of pulmonary hypertension and possibly greater coronary artery dilatation.

The present findings suggest that patients with progressive massive fibrosis, with or without bronchitis and emphysema, are protected from death from coronary artery disease and are more likely to die from congestive cardiac failure than are patients with simple pneumoconiosis either alone or with bronchitis and emphysema.

\section{REFERENCES}

Editorial (1969). Reversibility of pulmonary hypertension. Brit. med. J., 1, 201.

Gooding, C. G. (1946). Pneumoconiosis in South Wales anthracite miners. Lancet, 2, 891.

Gough, J. (1965). Pathological changes in the lungs associated with cor pulmonale. Bull. N.Y. Acad. Med., 41, 927.

Heath, D. (1968). In Form and Function in the Human Lung. Ed. Cumming, G., and Hunt, L. B., pp. 163, 168, 169. Livingstone, Edinburgh and London.

International Labour Office (1959). International classification of persistent radiological opacities in the lung fields provoked by the inhalation of mineral dusts. Occup. Safety Hlth, 9, 67.

Lavenne, F. (1951). Le retentissement cardio-vasculaire de la silicose et de l'anthraco-silicose. Rev. belge Path., 21, Suppl. 6.

(1968). Assessment of lung function in silicosis and mixed-dust pneumoconiosis. In Pneumoconiosis: Report on a Symposium convened by the Regional Office for Europe of the World Health Organization. p. 80. Katowice, June, 1967. W.H.O., Copenhagen.

Mitchell, R. S., Walker, S. H., and Maisel, J. C. (1968). The causes of death in chronic airways obstruction. II. Myocardial infarction. Amer. Rev. resp. Dis., 98, 611.

Wood, P. (1956). Diseases of the Heart and Circulation, 2nd ed., p. 850. Eyre and Spottiswoode, London.

Wyatt, J. P., and Ishikawa, S. (1968). In Form and Function in the Human Lung. Ed. Cumming, G., and Hunt, L. B., pp. 171, 173, 177. Livingstone, Edinburgh and London. 